\title{
Numerical Analysis of Printed Circuit Board with Thermal Vias: Heat Transfer Characteristics under Nonisothermal Boundary Conditions
}

\author{
Yasushi Koito, Yoshihiro Kubo, Toshio Tomimura \\ Department of Advanced Mechanical Systems, Kumamoto University, Kumamoto, Japan \\ Email: koito@gpo.kumamoto-u.ac.jp
}

Received September 25, 2013; revised October 25, 2013; accepted October 31, 2013

Copyright (C) 2013 Yasushi Koito, et al. This is an open access article distributed under the Creative Commons Attribution License, which permits unrestricted use, distribution, and reproduction in any medium, provided the original work is properly cited.

\begin{abstract}
A thermal via has been used to enhance the heat transfer through the printed circuit board (PCB). Because the thermal conductivity of a dielectric material is very low, the array of metal vias is placed to make thermal paths in the PCB. This paper describes the numerical analysis of the PCB having metal vias and focuses on the heat transfer characteristics under the nonisothermal boundary conditions. The mathematical model of the PCB has the metal vias between two metal sheets. Under 2nd and 3rd kinds of boundary conditions, the temperature distribution is obtained numerically by changing the design parameters. The discussion is also made on the effective thermal conductivity of the PCB. In industry, the use of effective thermal conductivity is convenient for thermal engineers because it simplifies the calculation process, that is, the composite board can be modeled as a homogeneous medium. From the numerical results, it is confirmed that the placement of metal sheets and the population of metal vias are important factors to dominate the heat transfer characteristics of the PCB. It is also shown that although the nonisothermal boundary conditions are applied at the boundary surface, the temperature difference between the heated and the cooled section is almost uniform when the metal vias are populated densely with the metal sheets. In this case, the effective thermal conductivity of the PCB is found to be the same irrespective of the boundary conditions, that is, whether the isothermal or the nonisothermal boundary conditions are applied.
\end{abstract}

Keywords: Thermal Management; Printed Circuit Board; Thermal Via; Effective Thermal Conductivity; Nonisothermal Boundary Condition

\section{Introduction}

Because of an increase in heat dissipation from electronics components placed on a printed circuit board (PCB), a thermal via has been used as one of the thermal solutions to enhance the heat transfer through the PCB. In many cases, the thermal via is a small hollow cylinder of copper, and their arrays are placed inside the board. The thermal conductivity of the metal via is about 1000 times higher than that of a dielectric material, and therefore the via serves effectively as a heat conduction path through the board.

Many studies have been published on the heat transfer characteristics of thermal vias. Lee et al. [1] conducted the analysis of thermal vias in a high density interconnect layer. A closed-form analytical model was presented using the Bessel functions. Nakayama [2] conducted a de- tailed analysis on the heat conduction in the PCB. This study dealt with a substrate for a ball grid array package, where a belt of densely populated through-vias and two continuous copper layers were placed. Li [3], on the other hand, addressed a simple model for the analysis of thermal vias. One-dimensional heat flow inside the PCB was assumed, and a calculation model was presented based on a thermal resistance network. Hatakeyama et al. [4] showed a two-dimensional thermal resistance network model of the thermal via. The model was verified by comparing calculation results with experimental ones. Furthermore, the effectiveness of the thermal via was shown by Guenin [5] and Kafadarova and Andonova [6] by changing the number of vias. Bissuel et al. [7] also showed the effectiveness of micro-via structures in the PCB.

In industry, thermal engineers use effective thermal 
conductivity for calculation of heat transfer through the PCB. The PCB is a composite board, where complicated metal wirings are placed in a dielectric material. The use of effective thermal conductivity simplifies the calculation process because the PCB can be modeled as a homogeneous medium.

Concerning the effective thermal conductivity of the PCB, the analytical studies were published by Culham and Yovanovich [8] and Shabany [9]. Culham and Yovanovich pointed out the importance of a spreading resistance as well as a metal resistance for the calculation of effective thermal conductivity. Shabany clarified the effects of a component (heat source) size and copper layers in the PCB on the evaluation of effective thermal conductivity. Moreover, Nakayama et al. [10] have launched the study to develop a scheme to estimate the effective thermal conductivity, which will be implemented into a system of computer codes.

This paper describes the numerical analysis on the heat transfer characteristics of the PCB having thermal vias. Unlike previous studies, the present analysis focuses on nonisothermal boundary conditions. Although the effect of boundary conditions on the effective thermal conductivity of the PCB was examined by Culham and Yovanovich [8] and Shabany [11], their models did not have the thermal vias. In the present analysis, under 2nd and 3rd kinds of boundary conditions, the temperature distribution and the effective thermal conductivity of the board are discussed by changing thermal design parameters. As described by Guenin [5] and Shabany [9], since a metal sheet is an important factor to dominate the heat transfer characteristics of the PCB, the metal sheets are also included in the present mathematical model.

\section{Analytical Method and Nonisothermal Boundary Conditions}

Numerical analysis is conducted for the simplified PCB shown in Figure 1. This model has metal vias (thermal conductivity: $\lambda_{v}$ ) inside a polymer board (thermal conductivity: $\lambda_{b}$ ) and two metal sheets (thicknesses: $\delta_{t s}, \delta_{b s}$, thermal conductivities: $\lambda_{t s}, \lambda_{b s}$ ) on the top and the bottom of the board. The top surface of the model is entirely heated while the bottom is entirely cooled, and the heat transfer characteristics of the model are analyzed in an $x-y-z$ coordinate system. The temperature distribution inside the model is obtained by solving the heat conduction equation given by

$$
\nabla \cdot\left(\lambda_{j} \nabla T\right)=0 \quad(j=v, b, t s, b s)
$$

where $\lambda_{j}$ is the thermal conductivity and $T$ the temperature. The subscripts $v, b, t s$ and $b s$ stand for the metal via, the polymer board, the top metal sheet and the bottom metal sheet, respectively.
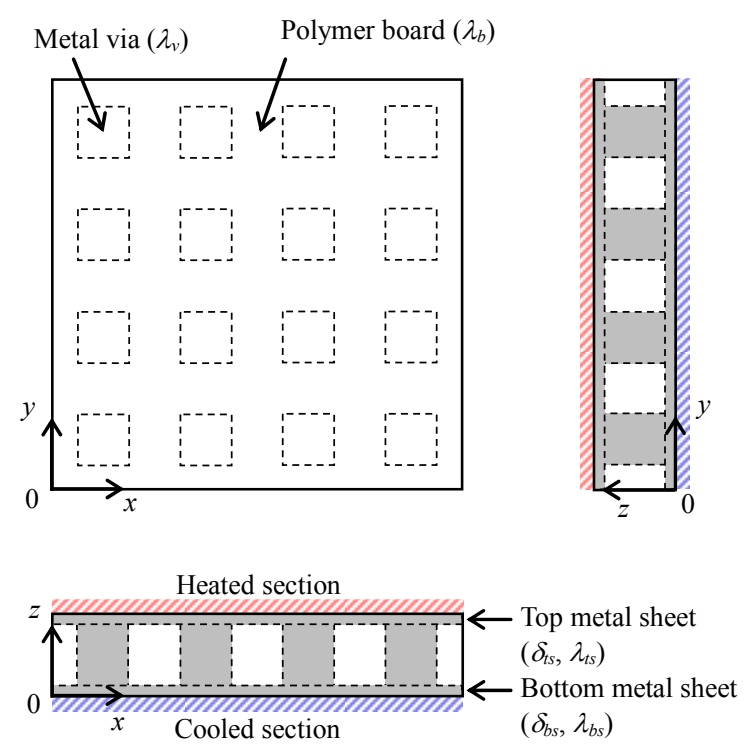

Figure 1. Mathematical model (thickness is exaggerated).

The temperature distribution and the effective thermal conductivity of the model are investigated as follows: First, the temperature distribution at the heated section (top surface) of the model is discussed under the boundary conditions of

$$
\begin{gathered}
-\lambda_{t s}(\partial T / \partial z)=q_{h} \text { at heated section, } \\
T=T_{c} \text { at cooled section, }
\end{gathered}
$$

where the heat flux, $q_{h}$, and the temperature, $T_{c}$, are given in calculation. Moreover, the temperature distribution at the cooled section (bottom surface) of the model is also discussed under the boundary conditions of

$$
\begin{gathered}
T=T_{h} \text { at heated section, } \\
-\lambda_{b s}(\partial T / \partial z)=\alpha\left(T-T_{f}\right) \text { at cooled section, }
\end{gathered}
$$

where the temperature, $T_{h}$, the heat transfer coefficient, $\alpha$, the cooling fluid temperature, $T_{f}$, are given.

Secondly, based on the numerical results obtained in the first investigation, the analysis is conducted on the effective thermal conductivity of the model. This discussion is made under the boundary conditions of

$$
\begin{gathered}
-\lambda_{t s}(\partial T / \partial z)=q_{h} \text { at heated section, } \\
-\lambda_{b s}(\partial T / \partial z)=\alpha\left(T-T_{f}\right) \text { at cooled section, }
\end{gathered}
$$

The nonisothermal boundary conditions are used at both sections.

Throughout the present analysis, the following adiabatic boundary condition is applied at the surfaces except for the heated and the cooled section:

$$
\partial T / \partial n=0
$$

where $n$ is the coordinate normal to the boundary surface. 
The analysis is conducted for the board having the size of $32 \mathrm{~mm} \times 32 \mathrm{~mm} \times 2.0 \mathrm{~mm}$ (thickness). The metal via array in the board is changed as shown in Figure 2. The specification of metal vias is shown in Table 1 . The metal via arrays are made keeping the total volume of vias in the board. The metal vias of Type 1 and Type 2 are too big compared with real ones; however, they are used here for comparison. Under the numerical conditions of $\lambda_{v}=$ $400 \mathrm{~W} /(\mathrm{m} \cdot \mathrm{K}), \lambda_{b}=0.40 \mathrm{~W} /(\mathrm{m} \cdot \mathrm{K}), T_{h}=40^{\circ} \mathrm{C}, q_{h}=5.0$ $\mathrm{W} / \mathrm{cm}^{2}$ and $T_{c}=T_{f}=20^{\circ} \mathrm{C}$, the thicknesses, $\delta_{t s}, \delta_{b s}$, the thermal conductivities, $\lambda_{t s}, \lambda_{b s}$, and the heat transfer coefficient, $\alpha$, are changed in the present analysis.

\section{Results and Discussion}

\subsection{Temperature Distribution}

Figure 3 shows the temperature distribution at the heated section (top surface) of the model. The numerical results are obtained under the boundary conditions of Equations (2) and (3). The three results for Type 1, Type 3 and Type 5 are compared at $\delta_{t s}=0.40 \mathrm{~mm}, \lambda_{t s}=400 \mathrm{~W} /(\mathrm{m} \cdot \mathrm{K})$, $\delta_{b s}=0 \mathrm{~mm}$ (without bottom metal sheet). The temperature distribution at the cross section is also shown in this figure. Since $\lambda_{v}$ is 1000 times higher than $\lambda_{b}$, the metal vias serve as main heat-flow paths through the board.

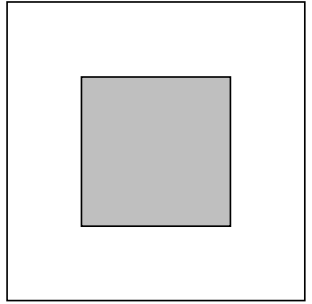

Type $1(N=1)$

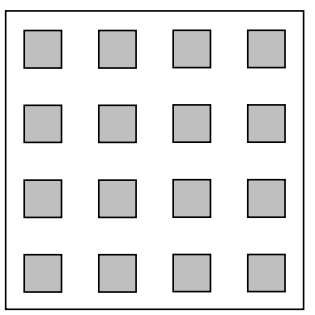

Type $3(N=16)$

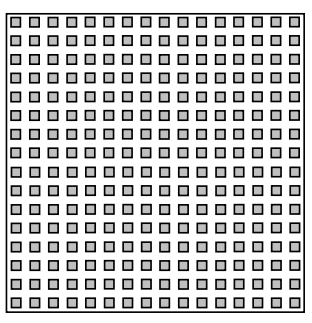

Type $5(N=256)$

Figure 2. Schematic diagram of via arrays.
Table 1. Specification of via.

\begin{tabular}{ccc}
\hline Type & Number & Cross-sectional area \\
\hline 1 & 1 & $16 \mathrm{~mm} \times 16 \mathrm{~mm}$ \\
2 & 4 & $8 \mathrm{~mm} \times 8 \mathrm{~mm}$ \\
3 & 16 & $4 \mathrm{~mm} \times 4 \mathrm{~mm}$ \\
4 & 64 & $2 \mathrm{~mm} \times 2 \mathrm{~mm}$ \\
5 & 256 & $1 \mathrm{~mm} \times 1 \mathrm{~mm}$ \\
\hline
\end{tabular}

Moreover, much difference is observed between the three numerical results, and therefore it is confirmed that the temperature distribution at the heated section is strongly affected by the arrangement of metal vias.

Under the same boundary conditions as used in Figure 3 , the temperature difference, $\Delta T$, between the heated and the cooled section of the model is obtained from the numerical results. The relations between $\Delta T$ and the number of vias, $N$, are shown in Figures 4 and 5, where $\delta_{t s}$ and $\lambda_{t s}$ are changed respectively at $\delta_{b s}=0 \mathrm{~mm}$. Because the temperature at the heated section is not uniform, the maximum and the minimum temperature difference, $\Delta T_{\max }, \Delta T_{\min }$, are shown in these figures. Irrespective of $\delta_{t s}$ and $\lambda_{t s}$, it is observed that $\Delta T_{\max }$ decreases while $\Delta T_{\min }$ increases slightly and therefore their difference becomes smaller with the increase in $N$. From Figure 4, it is found that in the cases of $\delta_{t s}=0.20 \mathrm{~mm}$ and $0.40 \mathrm{~mm}$, the temperature difference is less than $2.0^{\circ} \mathrm{C}$ at $N=64$ (Type 4) and $N=256$ (Type 5). However in the case of $\delta_{t s}=0 \mathrm{~mm}$, a large temperature difference is still observed at $N=256$. Therefore, although the metal vias are used in the board, their effectiveness is not demonstrated without the metal sheet. It is also confirmed that from Figure 5, $\Delta T_{\max }$ and $\Delta T_{\min }$ decrease and their difference becomes smaller with the increase in $\lambda_{t s}$. This is because of the decrease in thermal resistance of the top metal sheet.

Under the boundary conditions of Equations (4) and (5), the temperature distribution at the cooled section (bottom surface) of the model is obtained as shown in Figure 6. The numerical results for Type 1, Type 3 and Type 5 are compared at $\delta_{t s}=0 \mathrm{~mm}$ (without top metal sheet $), \delta_{b s}=0.40 \mathrm{~mm}, \lambda_{b s}=400 \mathrm{~W} /(\mathrm{m} \cdot \mathrm{K})$ and $\alpha=2000$ $\mathrm{W} /\left(\mathrm{m}^{2} \cdot \mathrm{K}\right)$. The temperature distribution at the cross section is also shown in this figure. Furthermore, the maximum and the minimum temperature difference, $\Delta T_{\max }$, $\Delta T_{\min }$, between the heated and the cooled section of the model are shown in Figure 7 changing $\alpha$ as a parameter. Convective and boiling heat transfers at the cooled section are considered in this calculation. The significant influence of via population is observed not only at the heated section but also at the cooled section. Moreover, because the heat flux is not prescribed at the boundary surface, the heat transfer rate through the model is increased 


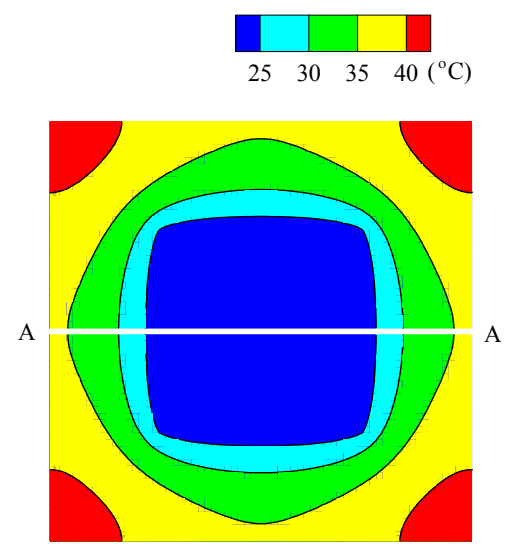

Cross section A-A

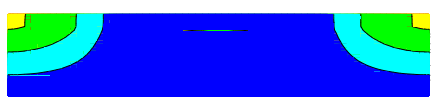

(a)

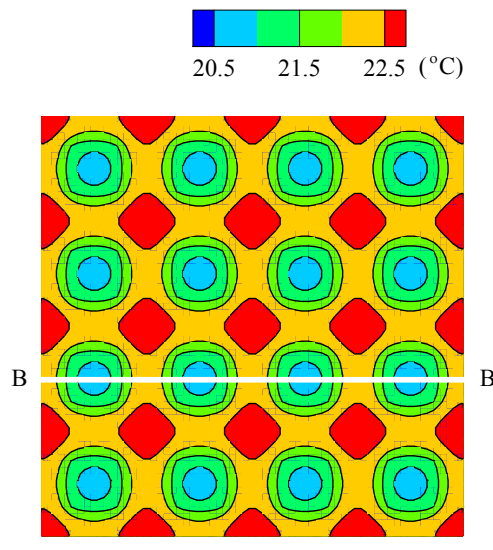

Cross section B-B

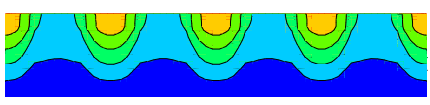

(b)

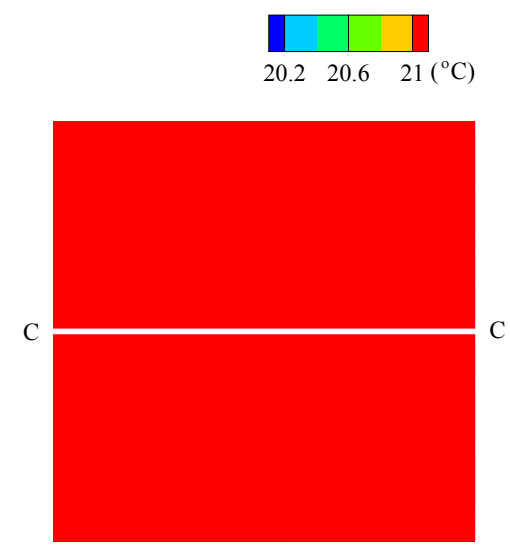

Cross section C-C

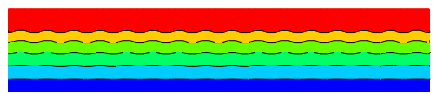

(c)

Figure 3. Temperature distributions at heated section and cross section $\left(\delta_{t s}=0.40 \mathrm{~mm}, \lambda_{t s}=400 \mathrm{~W} /(\mathrm{m} \cdot \mathrm{K}), \delta_{b s}=0 \mathrm{~mm}\right)$. (a) Type $1(N=1)$; (b) Type $3(N=16)$; (c) Type $5(N=256)$.
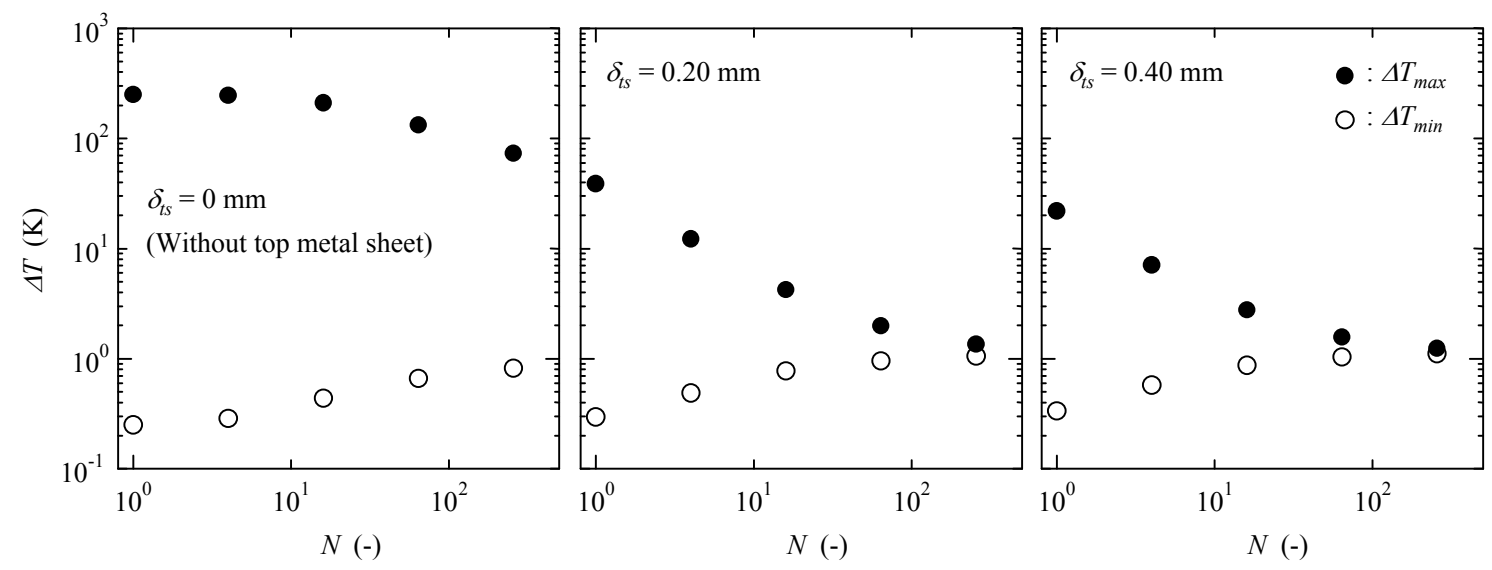

Figure 4. Temperature difference between heated and cooled section: effect of top sheet thickness $\left(\lambda_{t s}=400 \mathrm{~W} /(\mathrm{m} \cdot \mathrm{K}), \delta_{b s}=0\right.$ mm).
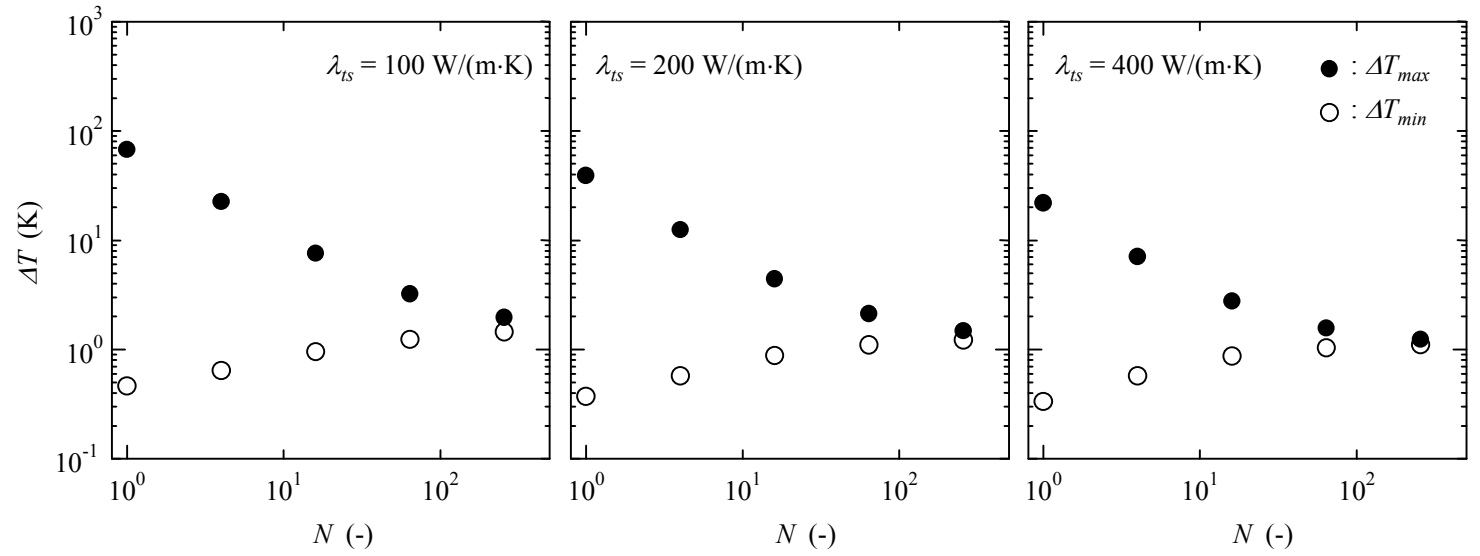

Figure 5. Temperature difference between heated and cooled section: effect of top sheet thermal conductivity $\left(\delta_{t s}=0.40 \mathrm{~mm}\right.$, $\delta_{b s}=0 \mathrm{~mm}$ ). 


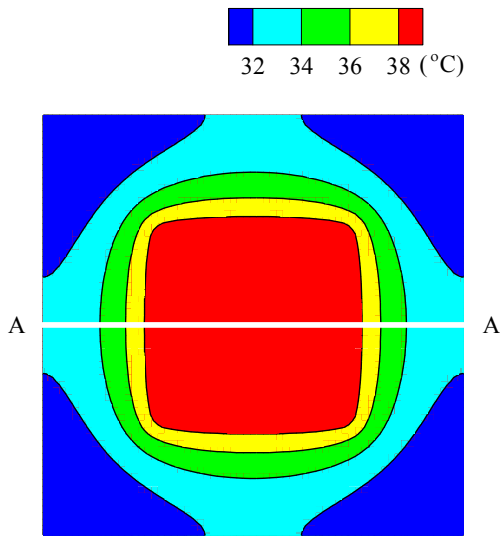

Cross section A-A

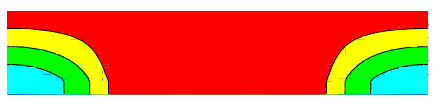

(a)
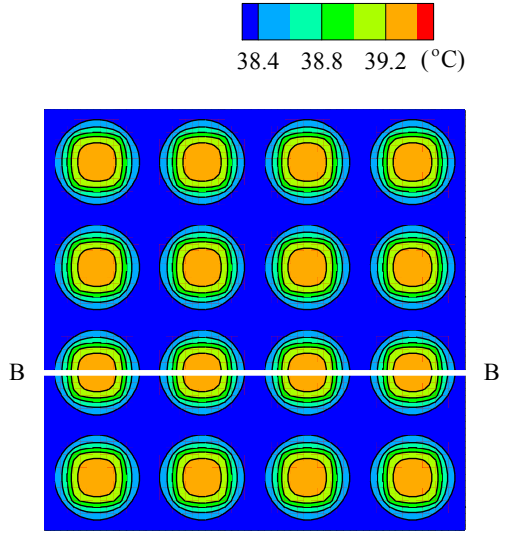

Cross section B-B

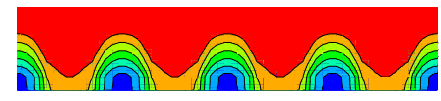

(b)

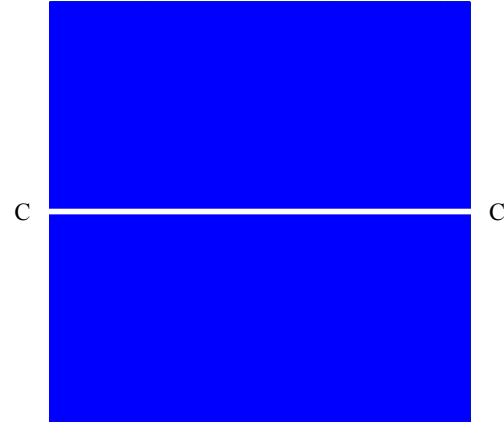

Cross section C-C

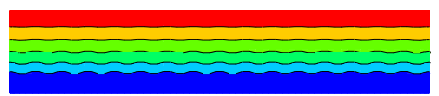

(c)

Figure 6. Temperature distributions at cooled section and cross section $\left(\delta_{t s}=0 \mathrm{~mm}, \delta_{b s}=0.40 \mathrm{~mm}, \lambda_{b s}=400 \mathrm{~W} /(\mathrm{m} \cdot \mathrm{K}), \alpha=\right.$ $\left.2000 \mathrm{~W} /\left(\mathrm{m}^{2} \cdot \mathrm{K}\right)\right)$. (a) Type $1(N=1)$; (b) Type $3(N=16)$; (c) Type $5(N=256)$.
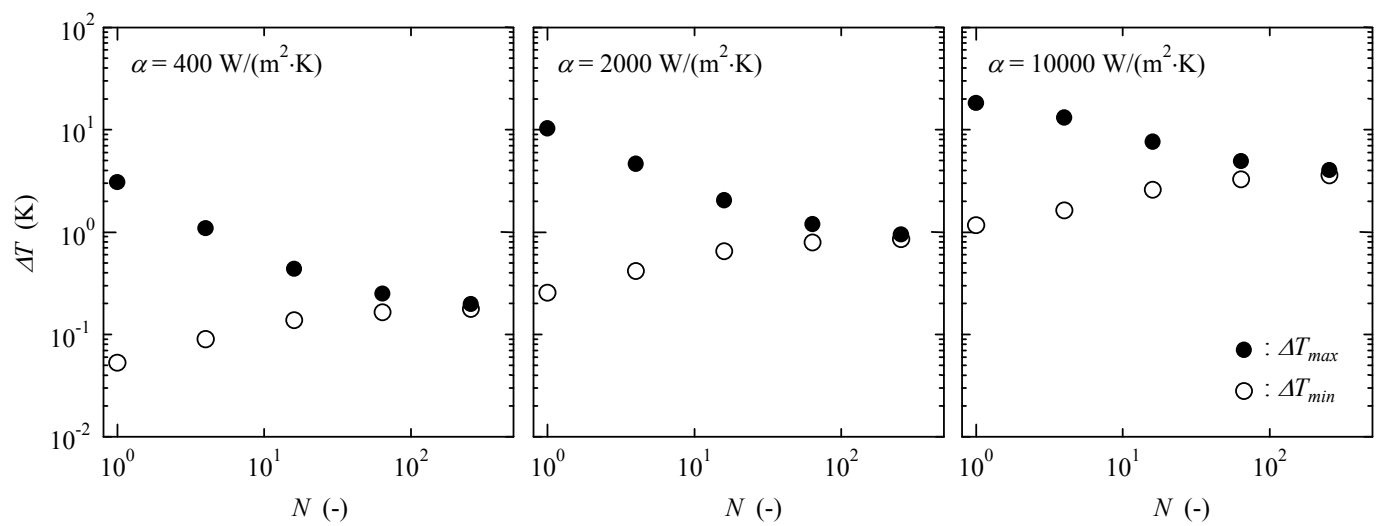

Figure 7. Temperature difference between heated and cooled section: effect of heat transfer coefficient at cooled section $\left(\delta_{t s}=\right.$ $\left.0 \mathrm{~mm}, \delta_{b s}=0.40 \mathrm{~mm}, \lambda_{b s}=400 \mathrm{~W} /(\mathrm{m} \cdot \mathrm{K})\right)$.

with $\alpha$, which causes to increase $\Delta T_{\max }$ and $\Delta T_{\min }$ as shown in Figure 7.

From the above numerical results under Equations (2), (3) and Equations (4), (5), it is confirmed that the placement of metal sheets and the population of metal vias are important factors to dominate the temperature distribution of the model. Although the nonisothermal boundary conditions are used at the boundary surface, the temperature difference between the heated and the cooled section is almost uniform when the metal vias are populated densely with the metal sheets. In the following section, the effective thermal conductivity of the model is discussed for Type 5 .

\subsection{Effective Thermal Conductivity}

The effective thermal conductivity, $\lambda_{\text {eff }}$, of the model is calculated by

$$
\lambda_{e f f}=q_{h}\left(\delta_{b s}+\delta_{b}+\delta_{t s}\right) / \Delta T
$$

Under the boundary conditions of Equations (6) and (7), the value of $\lambda_{\text {eff }}$ is obtained as shown in Figures 8-10. Because the temperatures at the heated and the cooled section of the model are not uniform as described above, $\Delta T_{\max }$ and $\Delta T_{\min }$ are used to calculate $\lambda_{\text {eff }}$, and the corresponding values of $\lambda_{\text {eff,min }}$ and $\lambda_{\text {eff,max }}$ are shown in these figures. Figure 8 shows the effect of $\delta_{t s}$ at $\lambda_{t s}=400$ $\mathrm{W} /(\mathrm{m} \cdot \mathrm{K}), \delta_{b s}=0.40 \mathrm{~mm}, \lambda_{b s}=400 \mathrm{~W} /(\mathrm{m} \cdot \mathrm{K})$ and $\alpha=$ $2000 \mathrm{~W} /\left(\mathrm{m}^{2} \cdot \mathrm{K}\right)$. Compared with the case of $\delta_{t s}=0 \mathrm{~mm}$ (without top metal sheet), it is found that the difference between $\lambda_{\text {eff,max }}$ and $\lambda_{\text {eff,min }}$ for $\delta_{t s} \neq 0 \mathrm{~mm}$ (with top metal sheet) is very small, and then the difference is reduced gradually with the increase in $\delta_{t s}$. The effectiveness of 


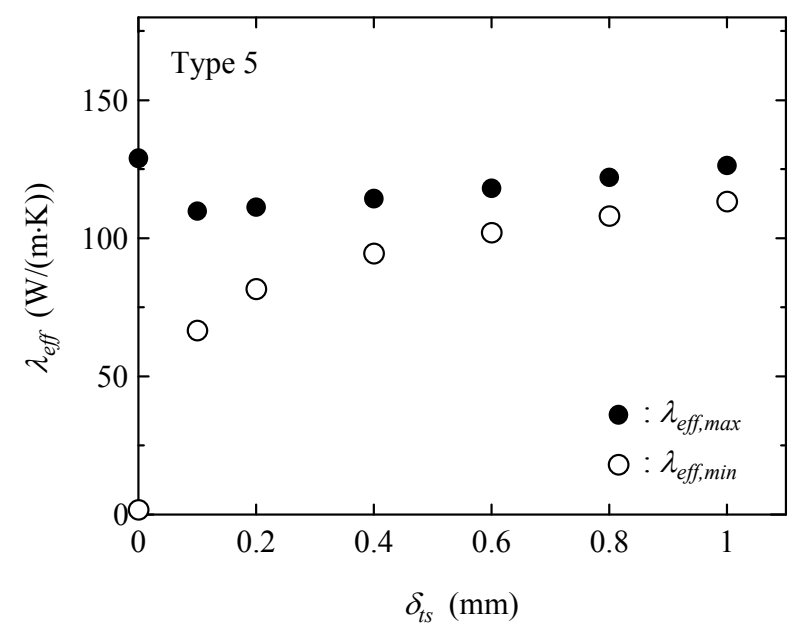

Figure 8. Effective thermal conductivity: effect of top sheet thickness $\left(\lambda_{t s}=400 \mathrm{~W} /(\mathrm{m} \cdot \mathrm{K}), \delta_{b s}=0.40 \mathrm{~mm}, \lambda_{b s}=400\right.$ $\left.\mathrm{W} /(\mathrm{m} \cdot \mathrm{K}), \alpha=2000 \mathrm{~W} /\left(\mathrm{m}^{2} \cdot \mathrm{K}\right)\right)$.

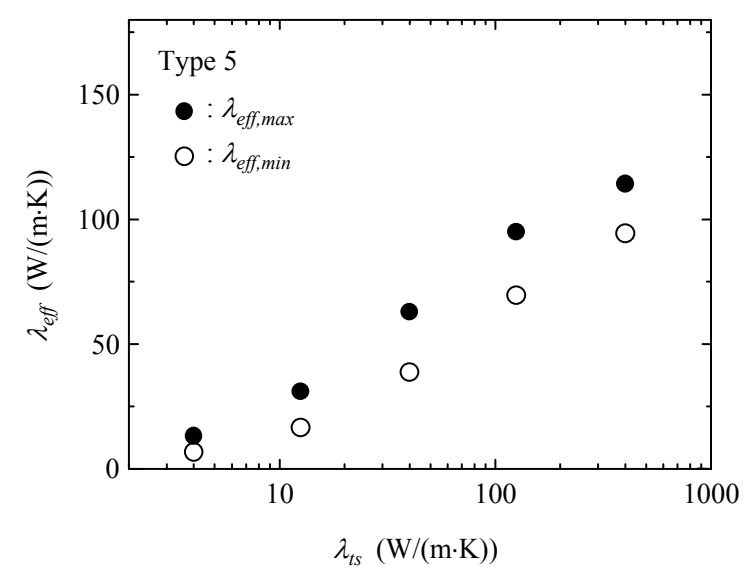

Figure 9. Effective thermal conductivity: effect of top sheet thermal conductivity $\left(\delta_{t s}=0.40 \mathrm{~mm}, \delta_{b s}=0.40 \mathrm{~mm}, \lambda_{b s}=400\right.$ $\left.\mathrm{W} /(\mathrm{m} \cdot \mathrm{K}), \alpha=2000 \mathrm{~W} /\left(\mathrm{m}^{2} \cdot \mathrm{K}\right)\right)$.

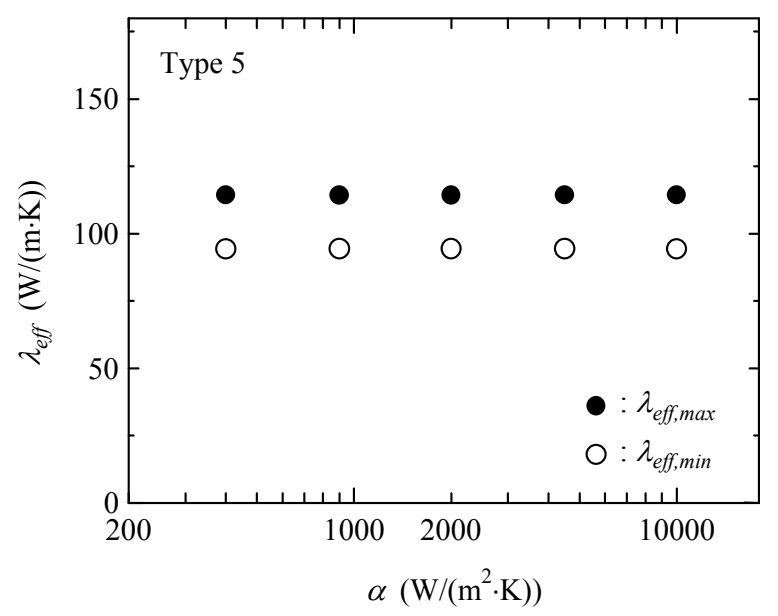

Figure 10. Effective thermal conductivity: effect of heat transfer coefficient at cooled section $\left(\delta_{t s}=0.40 \mathrm{~mm}, \lambda_{t s}=400\right.$ $\left.\mathrm{W} /(\mathrm{m} \cdot \mathrm{K}), \delta_{b s}=0.40 \mathrm{~mm}, \lambda_{b s}=400 \mathrm{~W} /(\mathrm{m} \cdot \mathrm{K})\right)$. metal sheet is confirmed although its thickness is several hundred microns. Figure 9 shows the effect of $\lambda_{t s}$ at $\delta_{t s}=$ $0.40 \mathrm{~mm}, \delta_{b s}=0.40 \mathrm{~mm}, \lambda_{b s}=400 \mathrm{~W} /(\mathrm{m} \cdot \mathrm{K})$ and $\alpha=$ $2000 \mathrm{~W} /\left(\mathrm{m}^{2} \cdot \mathrm{K}\right)$. Due to the increase in thermal resistance of the metal sheet, both $\lambda_{\text {eff,max }}$ and $\lambda_{\text {eff,min }}$ decrease with $\lambda_{t s}$, but their difference is still small even in the case when $\lambda_{t s}$ is less than $10 \mathrm{~W} /(\mathrm{m} \cdot \mathrm{K})$. Figure 10 shows the effect of $\alpha$ at $\delta_{t s}=0.40 \mathrm{~mm}, \lambda_{t s}=400 \mathrm{~W} /(\mathrm{m} \cdot \mathrm{K}), \delta_{b s}=0.40 \mathrm{~mm}$ and $\lambda_{b s}=400 \mathrm{~W} /(\mathrm{m} \cdot \mathrm{K})$. As described above, the heat transfer rate through the model is changed with $\alpha$; however, it is confirmed that $\lambda_{\text {eff,max }}$ and $\lambda_{\text {eff,min }}$ are hardly affected by $\alpha$.

The numerical analysis is also conducted under the isothermal boundary conditions expressed as

$$
\begin{gathered}
T=T_{h} \text { at heated section, } \\
T=T_{c} \text { at cooled section, }
\end{gathered}
$$

and then the corresponding value, $\lambda_{\text {eff }}^{\prime}$, of effective thermal conductivity is calculated by Equation (9). In this calculation, since the uniform temperatures are given at the heated and the cooled section, the temperature difference, $\Delta T$, is simply obtained by $\left(T_{h}-T_{c}\right)$. Besides, the heat flux, $q_{h}$, is calculated from the temperature gradient at the heated section. Figure 11 shows the ratio of $\lambda_{\text {eff }}$ to $\lambda_{\text {eff }}^{\prime}$, where $\delta_{t s}$ is changed at $\lambda_{t s}=400 \mathrm{~W} /(\mathrm{m} \cdot \mathrm{K}), \delta_{b s}=0.40 \mathrm{~mm}$, $\lambda_{b s}=400 \mathrm{~W} /(\mathrm{m} \cdot \mathrm{K})$ and $\alpha=2000 \mathrm{~W} /\left(\mathrm{m}^{2} \cdot \mathrm{K}\right)$. The maximum and the minimum value, $\lambda_{\text {eff, } \text { max }} / \lambda_{\text {eff }}^{\prime}, \lambda_{\text {eff, min }} / \lambda_{\text {eff }}^{\prime}$, are shown in this figure. The dashed lines are also used to indicate the difference in $\pm 10 \%$. Although the agreement between $\lambda_{\text {eff }}$ and $\lambda_{\text {eff }}^{\prime}$ depends on the design parameters, it is confirmed that the good agreement in $\pm 10 \%$ is obtained when the metal vias are populated densely with the metal sheets. In this case, the effective thermal conductivity is the same whether the isothermal or the nonisothermal boundary conditions are applied.

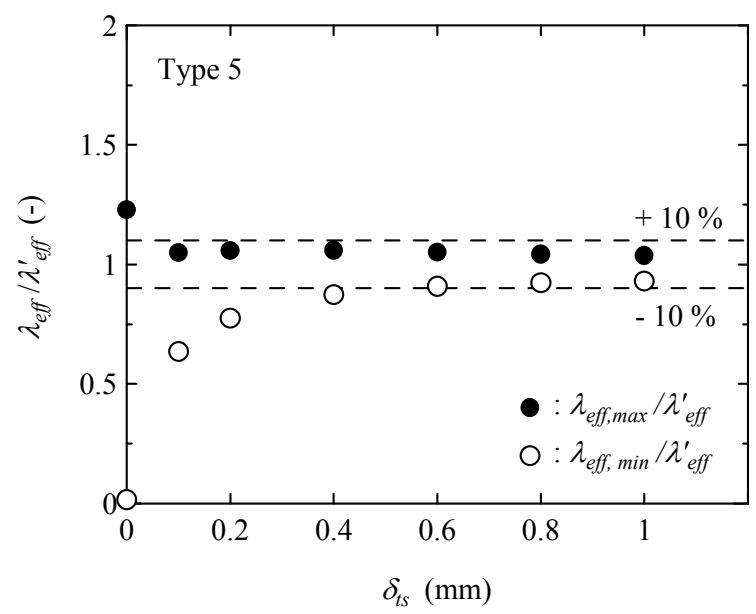

Figure 11. Comparison between isothermal and nonisothermal calculation: effect of top sheet thickness $\left(\lambda_{t s}=400\right.$ $\mathrm{W} /(\mathrm{m} \cdot \mathrm{K}), \delta_{b s}=0.40 \mathrm{~mm}, \lambda_{b s}=400 \mathrm{~W} /(\mathrm{m} \cdot \mathrm{K}), \alpha=2000$ $\left.\mathbf{W} /\left(\mathbf{m}^{2} \cdot \mathbf{K}\right)\right)$. 


\section{Conclusions}

Numerical analysis is conducted on the heat transfer characteristics of the $\mathrm{PCB}$, where the metal vias are placed between the metal sheets. Under 2 nd and 3rd kinds of boundary conditions, the temperature distribution and the effective thermal conductivity are obtained by changing the design parameters.

From the numerical results, it is confirmed that the placement of metal sheets and the population of metal vias strongly affect the heat transfer characteristics of the PCB. Although the nonisothermal boundary conditions are applied at the boundary surface, the temperature difference between the heated and the cooled section is almost uniform when the metal vias are populated densely with the metal sheets. In this case, the effective thermal conductivity of the PCB is found to be the same whether the isothermal or the nonisothermal boundary conditions are applied.

\section{REFERENCES}

[1] S. Lee, T. F. Lemczyk and M. M. Yovanovich, "Analysis of Thermal Vias in High Density Interconnect Technology," Proceedings of the 8th Annual IEEE Semiconductor Thermal Measurement and Management Symposium (SEMI-THERM), Austin, 3-5 February 1992, pp. 55-61. http://dx.doi.org/10.1109/STHERM.1992.172851

[2] W. Nakayama, "Heat Conduction in Printed Circuit Boards: A Mesoscale Modeling Approach," ASME Journal of Electronic Packaging, Vol. 130, No. 4, 2008, Article ID: 041106. http://dx.doi.org/10.1115/1.2993126

[3] R. S. Li, "Optimization of Thermal Via Design Parameters Based on an Analytical Thermal Resistance Model," Proceedings of the 6th InterSociety Conference on Thermal and Thermomechanical Phenomena in Electronic Systems (ITherm'98), Seattle, 27-30 May 1998, pp. 475-480. http://dx.doi.org/10.1109/ITHERM.1998.689605

[4] T. Hatakeyama, M. Ishizuka, S. Nakagawa and S. Takakuwa, "Thermal Resistance Measurement and Thermal Network Analysis of Printed Circuit Board with Thermal Vias," Proceedings of the ASME 2011 Pacific Rim Tech- nical Conference \& Exposition on Packaging and Integration of Electronic and Photonic Systems (InterPACK 2011), Portland, 6-8 July 2011, Article ID: 52168.

[5] B. Guenin, “Thermal Vias-A Packaging Engineer's Best Friend," Electronics Cooling, 2004.

http://www.electronics-cooling.com/2004/08/thermal-vias -a-packaging-engineers-best-friend/

[6] N. Kafadarova and A. Andonova, "PCB Thermal Design Improvement through Thermal Vias," Proceedings of the 8th WSEAS International Conference on Circuits, Systems, Electronics, Control \& Signal Processing (CSECS '09), Puerto De La Cruz, 14-16 December 2009, pp. 241244.

[7] V. Bissuel, M. Brizoux, A. Grivon, E. Monier-Vinard and F. Pires, "Impact of Printed Circuit Board Via and Micro-Via Structures on Component Thermal Performances," ASME Journal of Electronic Packaging, Vol. 133, No. 3, 2011, Article ID: 031013. http://dx.doi.org/10.1115/1.4004830

[8] J. R. Culham and M. M. Yovanovich, "Factors Affecting the Calculation of Effective Conductivity in Printed Circuit Boards," Proceedings of the 6th InterSociety Conference on Thermal and Thermomechanical Phenomena in Electronic Systems (ITherm'98), Seattle, 27-30 May 1998, pp. 460-467.

http://dx.doi.org/10.1109/ITHERM.1998.689603

[9] Y. Shabany, "Component Size and Effective Thermal Conductivity of Printed Circuit Boards," Proceedings of the 8th Intersociety Conference on Thermal and Thermomechanical Phenomena in Electronic Systems (ITherm 2002), San Diego, 29 May-1 June 2002, pp. 489-494. http://dx.doi.org/10.1109/ITHERM.2002.1012496

[10] W. Nakayama, K. Koizumi, T. Fukue, M. Ishizuka, T. Nakajima, H. Koike and R. Matsuki, "Thermal Characterization of High-Density Interconnects in the Form of Equivalent Thermal Conductivity," Proceedings of the ASME2009 InterPACK Conference (IPACK2009), San Francisco, 1923 July 2009, Article ID: 89086.

[11] Y. Shabany, "Effects of Boundary Conditions and Source Dimensions on the Effective Thermal Conductivity of a Printed Circuit Board," Proceedings of IPACK03 International Electronic Packaging Technical Conference and Exhibition, Maui, 6-11 July 2003, Article ID: 35201. 


\section{Nomenclature}

$N$ : number of via (-)

$n$ : coordinate normal to boundary surface $(\mathrm{m})$

$q$ : heat flux $\left(\mathrm{W} / \mathrm{cm}^{2}, \mathrm{~W} / \mathrm{m}^{2}\right)$

$T$ : temperature $\left({ }^{\circ} \mathrm{C}\right)$

$x, y, z$ : coordinate $(\mathrm{m})$

\section{Greek Symbols}

$\alpha$ : heat transfer coefficient $\left(\mathrm{W} /\left(\mathrm{m}^{2} \cdot \mathrm{K}\right)\right)$

$\Delta T$ : temperature difference $(\mathrm{K})$

$\delta$ : thickness $(\mathrm{mm})$

$\lambda$ : thermal conductivity $(\mathrm{W} /(\mathrm{m} \cdot \mathrm{K}))$

\section{Superscript}

': isothermal boundary condition

\section{Subscripts}

$b$ : polymer board

$b s$ : bottom metal sheet

$c$ : cooled section

eff: effective

$f$ : cooling fluid

$h$ : heated section

max: maximum

min: minimum

$t s:$ top metal sheet

$v$ : metal via 